Supporting information

\title{
An Exonuclease III Driven Dual-amplified Electrochemical Aptasensor Based on PDDA-Gr/PtPd@Ni-Co Hollow Nanoboxes for Chloramphenicol Detection
}

Senyao Wang ${ }^{1}$, Baoshan He ${ }^{1}$, Ying Liang ${ }^{2}$, Huali Jin ${ }^{1}$, Min Wei ${ }^{1}$, Wenjie Ren ${ }^{1}$, Zhiguang Suo ${ }^{1}$, Jinshui Wang $^{2}$

${ }^{1}$ School of Food Science and Technology, Henan University of Technology, Lianhua Road 100\#, Zhengzhou 450001, Henan Province, People's Republic of China

${ }^{2}$ College of Biological Engineering, Henan University of Technology, Lianhua Road 100\#, Zhengzhou 450001, Henan Province, People's Republic of China

* Corresponding author. Tel.: +86 371 67758022; Fax: +86 37167758022 E-mail addresss: hebaoshan@126.com 
Table S1. All the oligonucleotides used in this study.

\begin{tabular}{cl}
\hline \hline Name & \multicolumn{1}{c}{ Sequences (5’ to 3') } \\
\hline Aptamer & AGCAGCACAGAGGTCAGATGACTTCAGTGAGTTGTCCC \\
& ACGGTCGGCGAGTCGGTGGTAGCCTATGCGTGCTACCGT \\
& GAA $^{1}$ \\
cDNA & CCCAACTCACTGCCCC \\
hairpin DNA & AACATTTTCAACGAGCTTTTAAAATGTCAGTGAGTTGGG \\
capture DNA & GGGAGCTGCTACACGGGG-SH \\
assistant DNA & GGGTGTAGCAGCTCCCGCTCGTTGAAAATGTT \\
signal DNA & GTAGCAGCTCCC $-\mathrm{NH}_{2}$ \\
\hline \hline
\end{tabular}




\section{Synthesis of PDDA-Gr}

The synthesis of PDDA-Gr was based on the reported literature. ${ }^{2}$ Firstly, put 10 mg GO into $10 \mathrm{~mL}$ water, sonicated for two hours to disperse, and form a yellow-brown solution, after that unpeeled GO were removed via centrifugation at $8000 \mathrm{rpm}$ for $5 \mathrm{~min}$, the dispersion of GO was mixed with $50 \mu \mathrm{L}$ PDDA solution by magnetic stirring for $30 \mathrm{~min}$. Finally, add $50 \mu \mathrm{L}$ of hydrazine hydrate to the resulting mixture and react at 90 degrees for 24 hours. The black PDDA-functionalized graphene (PDDA-Gr) was collected by suction filtration, washed with deionized water, and dried at $60{ }^{\circ} \mathrm{C}$.

\section{Synthesis of ZIF-67 nanocubes and Ni-Co hollow nanoboxes}

The synthesis of the Ni-Co hollow nanoboxes refers to the previous literature with minor modifications. ${ }^{3}$ As a precursor for the preparation of Ni-Co hollow nanoboxes, ZIF-67 nanocubes was first prepared. Typically, $290 \mathrm{mg}$ of Co $\left(\mathrm{NO}_{3}\right)_{2} \cdot 6 \mathrm{H}_{2} \mathrm{O}$ was dissolved in $10 \mathrm{~mL}$ of deionized water containing $7.5 \mathrm{mg}$ of CTAB. Then the solution was quickly injected into $70 \mathrm{ml}$ of an ultrapure aqueous solution containing $4.540 \mathrm{~g}$ of 2-methylimidazole (the color immediately changed from colorless to purple) and stirred for 20 minutes, the product was collected by centrifugation and washed by ethanol for six times.

After preparing ZIF-67 nanocubes, the synthesis of Ni-CoHNBs was performed. First, disperse $30 \mathrm{mg}$ of the prepared ZIF-67 nanocubes in $20 \mathrm{~mL}$ of ethanol, then add $5 \mathrm{~mL}$ of ethanol solution containing $50 \mathrm{mg}$ of $\mathrm{Ni}\left(\mathrm{NO}_{3}\right)_{2}$, the solution was stirred for 1 minute and the product vessel was put into an ultrasonic bath (at low power) for 60 minutes. Finally, the product is washed with ethanol several times and dried at $70^{\circ} \mathrm{C}$.

\section{Synthesis of Pt@Ni-CoHNBs, Pd@Ni-CoHNBs and PtPd@Ni-Co HNBs}

Based on previous work, ${ }^{4} \mathrm{PtPd} @ \mathrm{Ni}-\mathrm{CoHNBs}$ was prepared by in-situ growth method. Disperse the prepared $2 \mathrm{mg} \mathrm{Ni}$-Co hollow nanoboxes in $2 \mathrm{~mL}$ deionized water, and then add $350 \mu \mathrm{L}$ of $\mathrm{H}_{2} \mathrm{PtCl}_{6}(1 \%)$ and $350 \mu \mathrm{L}$ of $\mathrm{Na}_{2} \mathrm{PdCl}_{4}(1 \%)$ 
respectively while stirring. After the solutions are thoroughly mixed, add $2 \mathrm{~mL}$ of PVP solution ( $2 \mathrm{mg} / \mathrm{mL}$ ). After that, the mixed solution was sonicated for 15 minutes, and then $2 \mathrm{ml}$ of $\mathrm{NaBH}_{4}(7.5 \mathrm{mg} / \mathrm{mL})$ was slowly added dropwise at 800rpm, and finally, the product was stirred at room temperature for 30 minutes, and centrifuged and washed 3 times to obtain PtPd@Ni-CoHNBs (by replacing the $\mathrm{Na}_{2} \mathrm{PdCl}_{4}$ solution and $\mathrm{H}_{2} \mathrm{PtCl}_{6}$ solution with equal amounts of PBS solution respectively to prepared Pd@Ni-CoHNBs andPt@Ni-CoHNBs).

\section{Preparation of signal probes}

The preparation of signal probes (HP-Uio-66/MB/signal DNA) was mostly refers to reported literature. ${ }^{5}$ First, $320 \mathrm{mg} \mathrm{ZrCl}_{4}$ and $9.6 \mathrm{~g}$ dodecanoic acid were dissolved in $80 \mathrm{ml}$ of DMF and then ultrasonically mixed for $30 \mathrm{~min}$. Subsequently, add $\mathrm{H}_{2} \mathrm{~N}-\mathrm{H}_{2} \mathrm{BDC}$ and continue ultrasonicated for $5 \mathrm{~min}$ (The molar ratio of $\mathrm{Zr} / \mathrm{BDC} /$ dodecanoic acid $=1 / 0.5 / 35)$. The mixed solution was transferred into a hydrothermal reaction kettle in oven at $120{ }^{\circ} \mathrm{C}$ for $48 \mathrm{~h}$, centrifuged and dried to obtain yellow powder. The powder sample was washed several times with DMF and then washed with ethanol several times, and finally dried at $120^{\circ} \mathrm{C}$ for $12 \mathrm{~h}$ to obtain HP-UiO-66- $\mathrm{NH}_{2}$ (Do not add dodecanoic acid during the preparation process to prepare traditional Uio-66- $\mathrm{NH}_{2}$, subsequent preparation process was consistent with HP-Uio-66- $\mathrm{NH}_{2}$.)

The preparation of signal probes was based on previous literature with minor modification. ${ }^{6}$ First, dispersed $24 \mathrm{mg}$ of $\mathrm{HP}-\mathrm{UiO}-66-\mathrm{NH}_{2}$ in $8 \mathrm{~mL}$ of $\mathrm{MB}(1 \mathrm{mM})$ and mixed for $24 \mathrm{~h}$ using magnetic stirrer. The obtained product was washed with PBS buffer several times to remove unbound MB. Subsequently, the product 
(HP-Uio-66/MB) was dispersed in $5 \mathrm{~mL}$ PBS buffer (pH 7.4) containing 2.5\% glutaraldehyde, and stirred at low speed for 2 hours. After that, the product was washed several times with PBS buffer. Finally, the $200 \mu \mathrm{L}$ of obtained MB/HP-Uio-66/ glutaraldehyde was incubated with $200 \mu \mathrm{L}$ of signal DNA (10 $\mu \mathrm{M})$ at $4{ }^{\circ} \mathrm{C}$ overnight to obtain HP-Uio-66/MB/signal DNA. The control group used Uio-66- $\mathrm{NH}_{2}$ instead of $\mathrm{HP}-\mathrm{UiO}-66-\mathrm{NH}_{2}$. Store the prepared signal probes at $4{ }^{\circ} \mathrm{C}$ before use.

\section{Preparation of capture probes (capture DNA-assistant DNA)}

First, $100 \mu \mathrm{L}$ of capture DNA $(8 \mu \mathrm{M})$ is mixed with $100 \mu \mathrm{L}$ of assistant DNA (8 $\mu \mathrm{M})$, then the mixed solution is heated to $95^{\circ} \mathrm{C}$ for 5 minutes, cooled to room temperature and left for two hours to form a double-stranded structure (capture DNA-assistant DNA). The capture probes were stored at $4{ }^{\circ} \mathrm{C}$ before use. 
Table S2. The EIS data of each modification steps.

\begin{tabular}{cc}
\hline \hline Curve & Ret ( $\mathbf{\Omega})$ \\
\hline a & 171.6 \\
b & 32.8 \\
c & 16.1 \\
d & 250.8 \\
e & 334.6 \\
f & 196.9 \\
g & 445.8 \\
\hline \hline
\end{tabular}




\section{Characterization of nanomaterials}
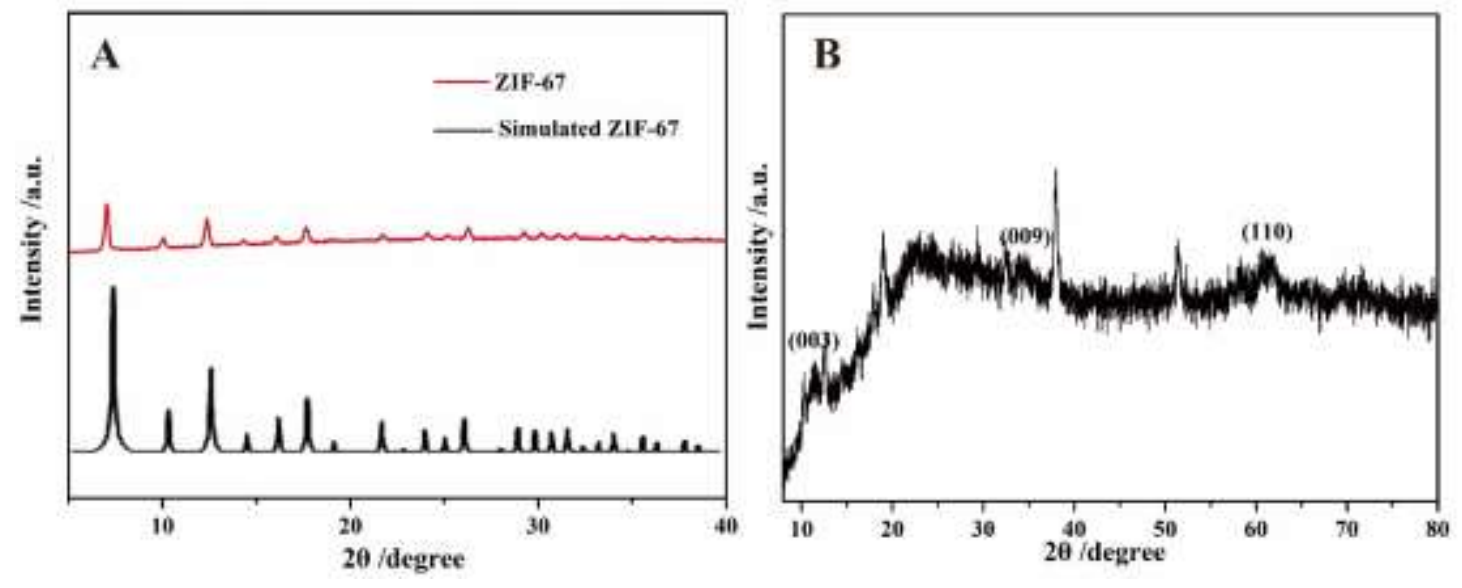

Figure S1. XRD patterns of (A) ZIF-67 and (B) Ni-CoHNBs. 


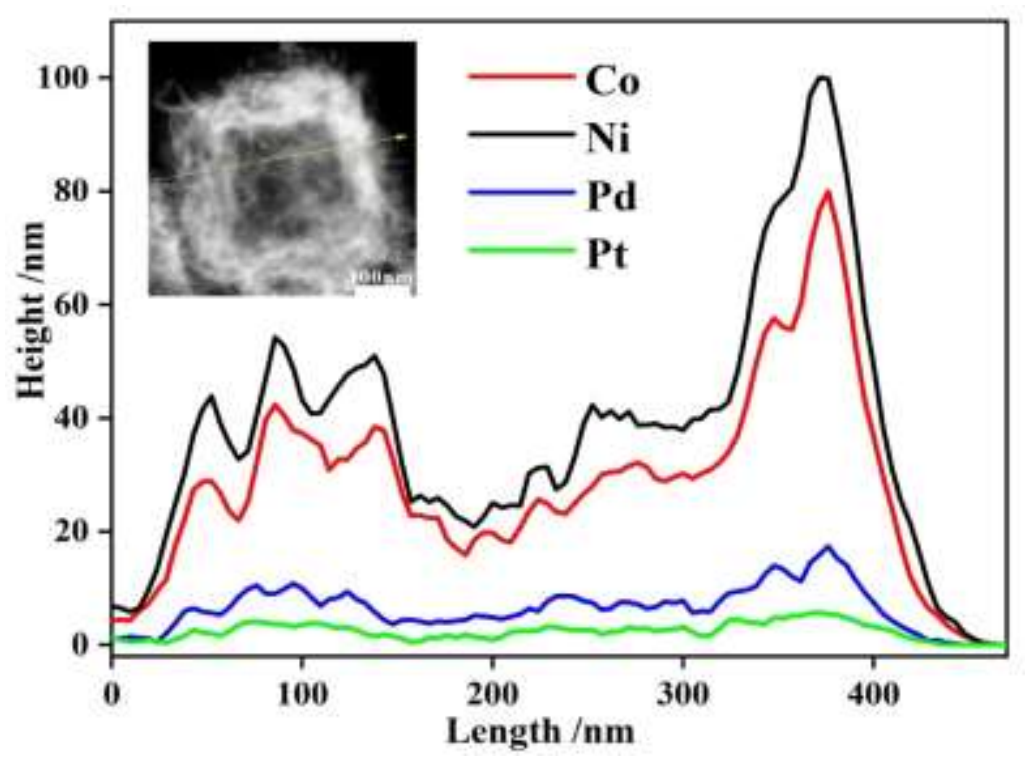

Figure S2. Elemental line scan of the PtPd@Ni-CoHNBs. 

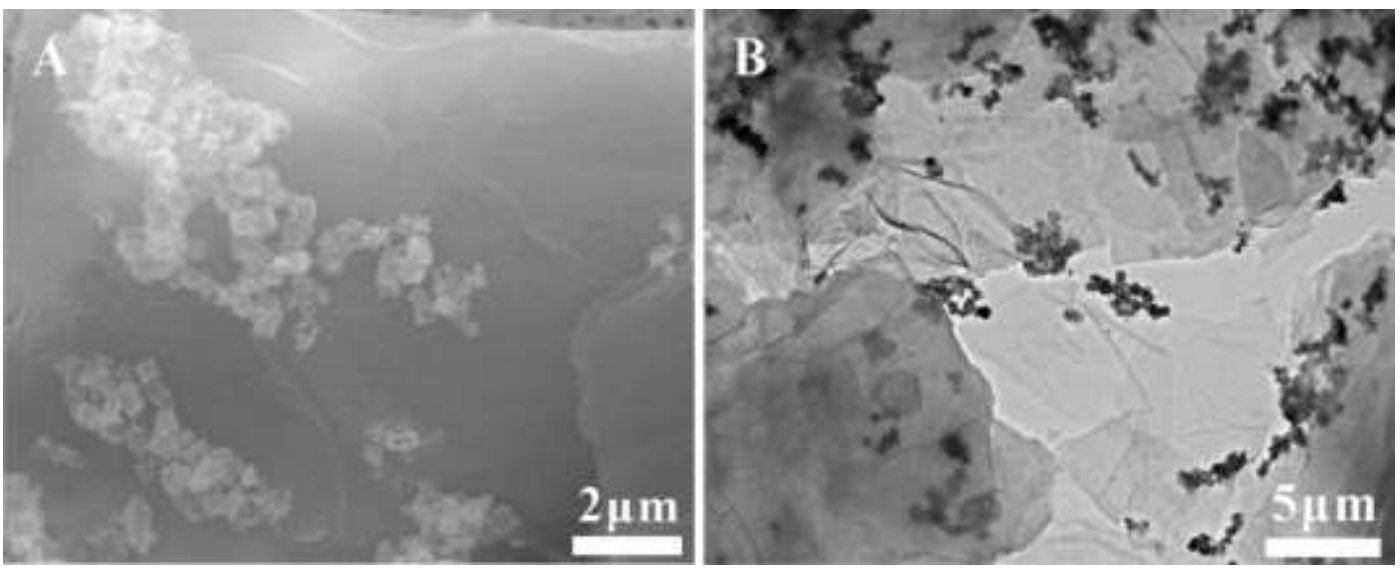

Figure S3. (A) SEM and (B) TEM images of PDDA-Gr/PtPd@ Ni-CoHNBs. 

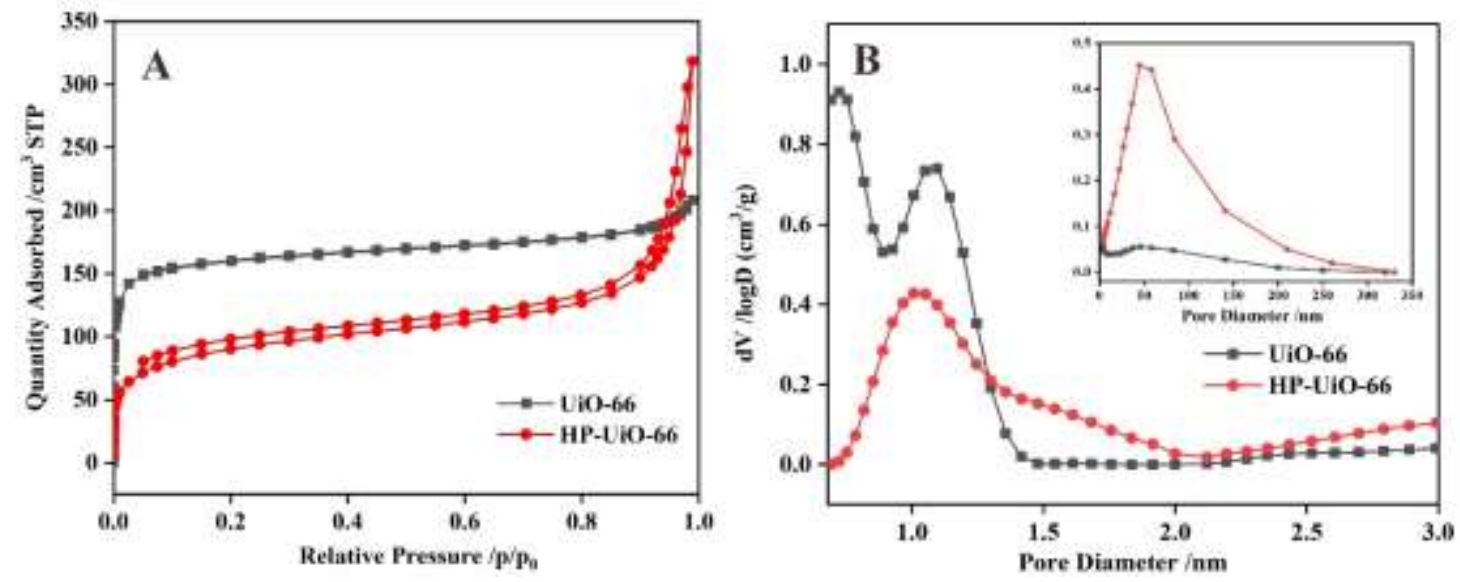

Figure S4. (A) $\mathrm{N}_{2}$ adsorption-desorption isotherms and (B) pore size distributions of UiO-66 and HP-UiO-66. 


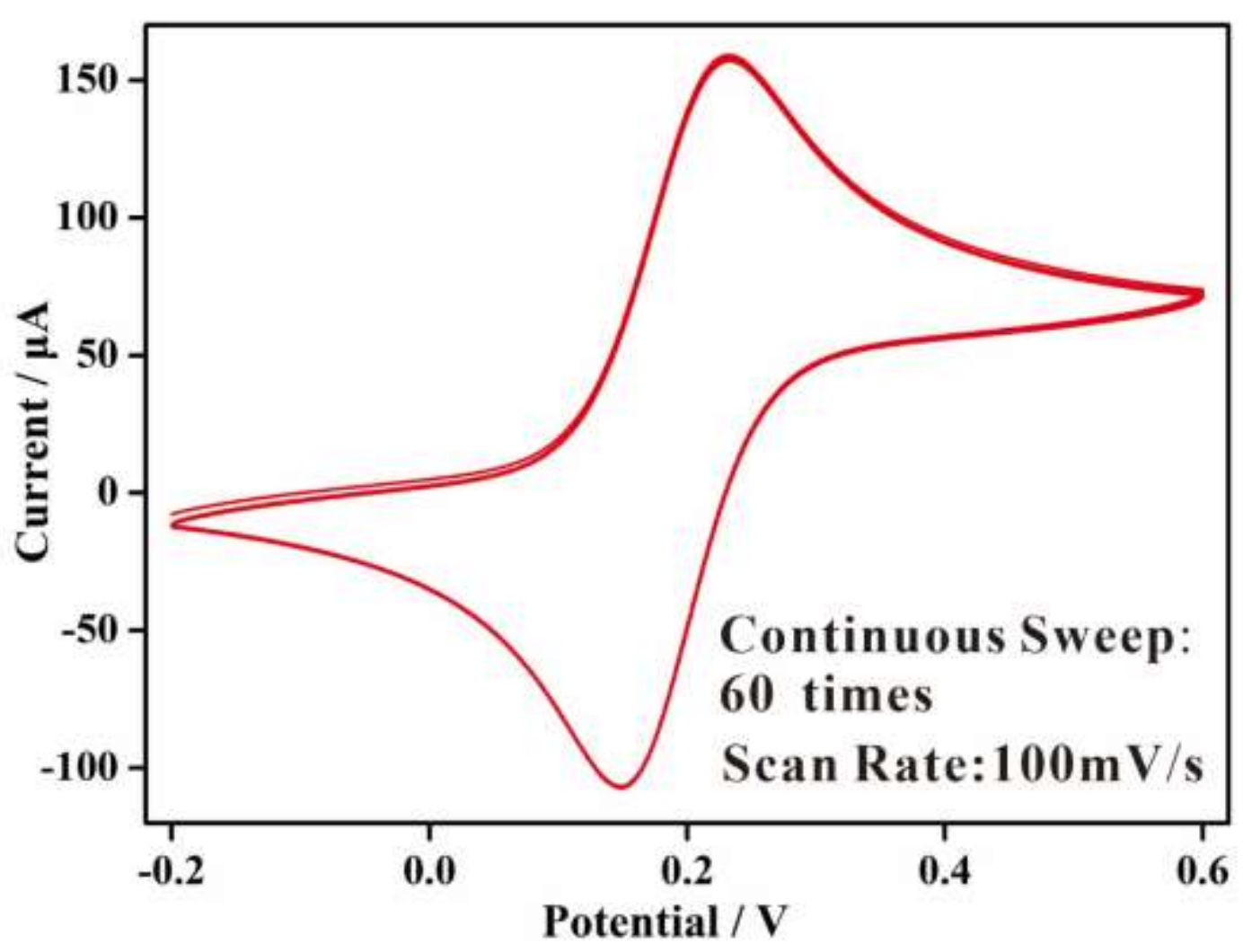

Figure S5. CV of PDDA-Gr/PtPd@Ni-CoHNBs/AuE (sweep speed: $0.1 \mathrm{~V} / \mathrm{s}$ ) continuous sweep 60 times. 


\section{Optimization of experimental conditions}

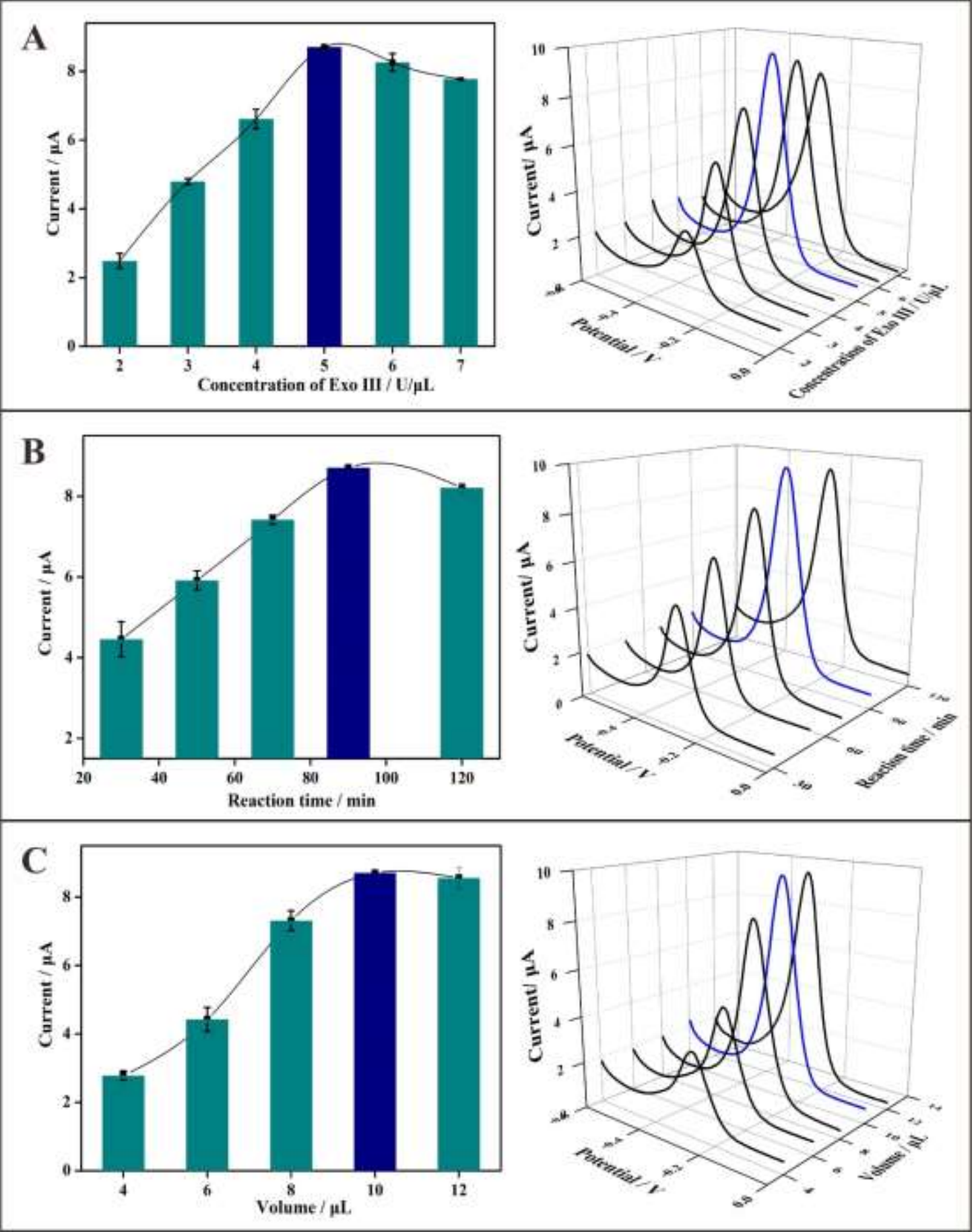

Figure S6. Optimization of experimental conditions: (A) the concentration of Exo III in cycle 2,

(B) the Exo III reaction time and (C) signal probes volume. DPV were measured in PBS buffer and the above experiments were carried out based on 1nM CAP. Get error bars from the standard deviation of three experiments. 
Experimental conditions play essential roles in achieving the best analytical performance, so several experimental conditions such as the concentration of Exo III in cycle 2, the Exo III reaction time, and signal probes volume are then optimized. First, $2 \mu \mathrm{L}$ of Exo III of different concentrations (2.0-7.0 U/ $\mu \mathrm{L})$ and $10 \mu \mathrm{L}$ of sample solution containing $1 \mathrm{nM}$ CAP are added to the electrode surface, and then the final DPV signal was measured. As shown in Figure S6A, the DPV signal reaches the peak value when the concentration of Exo III is $5 \mathrm{U} / \mu \mathrm{L}$, after that the signal does not improve obviously with the increase in Exo III concentration. Therefore, for the following experiments, $5.0 \mathrm{U} / \mu \mathrm{L}$ was determined as the concentration of Exo III.

As another important factor, the temporal response of Exo III reaction time was also examined. A time-dependent change of the electrochemical signal is shown in Figure S6B. The electrochemical response increases continuously and almost reaches a plateau at the incubation time of $90 \mathrm{~min}$. Thus $90 \mathrm{~min}$ was regarded as the optimal reaction time for the subsequent experiment.

The volume of signal probes modification was studied by adding 4-12 $\mu \mathrm{L}$ HP-Uio-66/MB/signal DNA. Figure S6C shows that the DPV peak signal increased with the volume of signal probes ranging from 4 to $10 \mu \mathrm{L}$, and it started to remain relatively constant at a much higher volume. This manifested that the binding sites in the aptasensor had approached saturation. Therefore, the signal probes of $10 \mu \mathrm{L}$ was pinpointed as the optimal value. 


\section{Calculation method of detection limit}

we calculated the detection limit according to the following method:

According to IUPAC recommendation (IUPAC 1976), the analyte's signal at the detection limit ( $\mathrm{Sdl})$ is given by:

$$
\mathrm{Sdl}=\text { Sreag }+\mathrm{k} * \text { oreag, }
$$

where Sreag is the electrochemical signal for a blank, oreag is the known standard deviation for the blank's electrochemical signal $(n=10)$. As is well known, $\mathrm{k}=$ signal/noise $(\mathrm{S} / \mathrm{N})=3$. As suggested by Long and Winefordner (1983) (Long and Winefordner 1983), the use of $\mathrm{k}=3$ allows a confidence level of $99.86 \%$ for a normal distribution of the blank signals. The detection limit can be calculated by Sdl and calibration curves. 


\begin{tabular}{ccccc}
\hline \hline Number & $I(-\mu \mathrm{A})$ & Average & SD & RSD $(\%)$ \\
\hline 1 & 2.32 & & \\
2 & 2.06 & & \\
3 & 1.99 & & \\
4 & 1.90 & & \\
5 & 2.13 & & \\
6 & 2.014 & & \\
7 & 1.90 & & \\
8 & 2.04 & & \\
9 & 2.02 & & \\
10 & 1.90 & & \\
\hline \hline
\end{tabular}

Table S3. Electrochemical response values of the blank solution for ten times 


\section{References}

1. Mehta, J.; Van Dorst, B.; Rouah-Martin, E.; Herrebout, W.; Scippo, M.-L.; Blust, R.; Robbens, J., In vitro selection and characterization of DNA aptamers recognizing chloramphenicol. J. Biotechnol. 2011, 155 (4), 361-369.

2. Liu, K. P.; Zhang, J. J.; Yang, G. H.; Wang, C. M.; Zhu, J. J., Direct electrochemistry and electrocatalysis of hemoglobin based on poly(diallyldimethylammonium chloride) functionalized graphene sheets/room temperature ionic liquid composite film. Electrochem. Commun. 2010, 12 (3), $402-405$.

3. He, P.; Yu, X.-Y.; Lou, X. W., Carbon-Incorporated Nickel-Cobalt Mixed Metal Phosphide Nanoboxes with Enhanced Electrocatalytic Activity for Oxygen Evolution. 
Angew. Chem. Int. Ed. 2017, 56 (14), 3897-3900.

4. Yu, Y.; Yu, C.; Niu, Y.; Chen, J.; Zhao, Y.; Zhang, Y.; Gao, R.; He, J., Target triggered cleavage effect of DNAzyme: Relying on Pd-Pt alloys functionalized Fe-MOFs for amplified detection of Pb2+. Biosens. Bioelectron. 2018, 101, 297-303.

5. Kandiah, M.; Nilsen, M. H.; Usseglio, S.; Jakobsen, S.; Olsbye, U.; Tilset, M.; Larabi, C.; Quadrelli, E. A.; Bonino, F.; Lillerud, K. P., Synthesis and Stability of Tagged UiO-66 Zr-MOFs. Chem. Mater. 2010, 22 (24), 6632-6640.

6. Cai, G.; Jiang, H.-L., A Modulator-Induced Defect-Formation Strategy to Hierarchically Porous Metal-Organic Frameworks with High Stability. Angew. Chem. Int. Ed. 2017, 56 (2), 563-567. 